Research Article

\title{
Local Thickening and Friction Reducing to Constant Resistance in a Prefolded Energy Absorption Device
}

\author{
Hailiang Xu, ${ }^{1}$ Jiaqi Song $\mathbb{D}^{1},{ }^{1}$ Dong An, ${ }^{1}$ Yimin Song $\mathbb{D}^{1},{ }^{1}$ and Xiangfeng $\mathrm{Lv}^{2}$ \\ ${ }^{1}$ School of Civil Engineering, North China University of Technology, Beijing 100144, China \\ ${ }^{2}$ School of Civil and Resource Engineering, University of Science and Technology Beijing, Beijing 100083, China \\ Correspondence should be addressed to Yimin Song; ssyymmok@sina.com
}

Received 21 January 2020; Revised 3 July 2020; Accepted 13 July 2020; Published 27 July 2020

Academic Editor: Francisco Beltran-Carbajal

Copyright (c) 2020 Hailiang Xu et al. This is an open access article distributed under the Creative Commons Attribution License, which permits unrestricted use, distribution, and reproduction in any medium, provided the original work is properly cited.

The energy absorption support for impact resistance used in mining engineering is a prefolded energy absorption device. In this paper, through the quasistatic compression test and numerical simulation, the relationship between the deformation process, load-displacement curve, and plastic strain of the original prefolded energy absorbing device is studied. It is found that the concave side stiffness has an obvious effect on the first and second descending sections of the load-displacement curve, and the friction coefficient has an obvious effect on the second ascending section of that. In order to make the prefolded energy absorption device reach the state of constant resistance where the reaction load does not fluctuate or the fluctuation is small in the crushing process, the plastic strain is restrained by thickening the local area of the concave side, which effectively reduces the descending amplitude of the load-displacement curve. Whether continuoues deformation occurs is affected by the friction coefficient. Finally, a constant resistance energy absorption device is designed by thickening the concave side and reducing the friction coefficient. Compared with the original structure, the maximum bearing capacity of the constant resistance energy absorption device is basically unchanged, the average bearing capacity is increased by $29 \%$, the total energy absorption is increased by $111 \%$, the specific energy absorption is increased by $119 \%$, and the load-displacement curve variance is reduced to $3 \%$ of the original structure.

\section{Introduction}

Rock burst is one of the main disasters threatening the safety of coal mining in China. With the continuous strengthening of mining intensity and depth, the disaster caused by rock burst is more and more serious $[1,2]$. According to the statistical data, it shows that more than $90 \%$ of the rock burst occurs in the tunnel. It has become a consensus in the field of coal to strengthen support and solve the problem of rock burst. In the aspect of roadway rock burst support, rigid support technologies such as single hydraulic support, pipe shed support, and anchor bolt support are put forward. Scholars have also conducted a lot of research on rigid support technology. For example, under the action of dynamic load, adding yield element can significantly improve the coordination of bolt support and arch yield support $[3,4]$. From the effect of field application, the rigid support is difficult to ensure the stability of the whole system and the integrity of the surrounding rock when facing the sudden vibration and impact of the surrounding rock $[5,6]$. Energy absorption support is an important method to solve the impact damage of the support body when the rock burst occurs [7]. As an important component of energy absorption support, the energy absorption device protects the system from damage by transforming the impact energy into plastic deformation and alleviating the impact of surrounding rock [8]. Therefore, it is of great significance to improve the energy absorption effect of the energy absorption device to solve the support problem of the rock burst tunnel.

As an important collision kinetic energy dissipation device, the energy absorption device has been applied in automobile, aircraft, ship, high-speed rail, and other traffic fields [9-11] and has achieved good results. The most used energy absorbing devices in the recent years, including 
square tubes, circular pipes, multicell tubes, and foam filled pipes, have been studied more thoroughly [12-21]. Taking the circular tube as an example, according to the ratio of length to diameter, the circular tube can be divided into three modes: the simple compression mode [22], progressive folding mode [23], and overall buckling mode [24]. In the simple compression mode, the compression load is large with short stroke; nevertheless, the overall buckling mode will sharply reduce the load, both of which are not conducive to the energy absorption of the circular tube. The progressive folding mode has a long compression stroke and a stable compression load, which means the energy absorption effect is good, only occurs when the length of the circular tube is 5 times the radius [25]. In mining engineering, the height of tunnel is generally about $4 \mathrm{~m}$ (taking the Gengcun Coal Mine and Changcun Coal Mine in China as examples), except for the height of support structure, the height of arrangement of the energy absorption device is limited by the height and deformation mode, and the radius of the circular pipe will be very small, which leads to the total amount of energy absorption of the circular pipe to be very small, so it is difficult to meet the engineering demand. Therefore, the energy absorption device commonly used in mining engineering is a prefolded energy absorption device [26]. The energy absorption device is placed at the bottom of the hydraulic support (as shown in Figure 1), which has been applied in the Gengcun mine and Changcun mine (as shown in Figure 2). The device can guide the deformation under the vertical pressure by setting the crease in advance, so that it can have a stable deformation mode under the axial impact, thus obtaining a stable energy absorption effect. Compared with the traditional square tube, the prefolded device has a lower collapse peak load, higher total energy absorption and specific energy absorption, and better energy absorption effect [27]. Ma et al. [28, 29] studied the energy absorption effect of single and double sections of the energy absorption device and the angle of prefolded. The results show that the effect of the single section energy absorption device is better than that of double sections, and the energy absorption effect of the energy absorption device is the best when the plate angle is $156^{\circ}$. Pan Yishan [30] added porous metal materials to the energy absorption device to increase the support damping of the energy absorption component and improve the energy absorption effect. According to references $[7,8,26-30]$ and the experiments in this paper, it is found that the load-displacement curve of the energy absorption device in the process of axial collapse presents a "near W" fluctuation. Hanssen et al. and Yang et al. [22, 24] mentioned the index to measure the energy absorption effect, and the load-displacement curve of the energy absorption structure in the ideal state should maintain the constant resistance state where the load does not fluctuate or the fluctuation is small. At present, reducing the fluctuation of the loaddisplacement curve of the energy absorption device makes it reach the ideal constant resistance state, and the energy absorption effect will be greatly improved.

In this paper, the folding process and mechanical properties of the device are studied by the quasistatic compression test and numerical simulation. The results show that the friction coefficient of the contact surface and the stiffness of the concave side wall have a great influence on the load-displacement curve of the energy absorbing device. Furthermore, the curves are segmented and the components are partitioned, and the plastic strain of the energy absorption device is analysed. Finally, a new type of a constant resistance structure is designed by reducing the friction coefficient and local thickening of concave sides wall.

\section{Mechanical Properties}

\subsection{Quasistatic Compression Test and Numerical Simulation}

2.1.1. Situation. In order to study the bearing effect and energy absorption capacity of the prefolded energy absorption device (hereinafter referred to as the device), the quasistatic compression test is carried out for the device. The steel density used in the energy absorption device is $7980 \mathrm{~kg} /$ $\mathrm{m}^{3}$, elastic modulus is $250 \mathrm{GPa}$, Poisson's ratio is 0.3 , yield strength is $890 \mathrm{MPa}$, and the ultimate strength is $1050 \mathrm{MPa}$. The loading system adopts an RLJW-2000 hydraulic servo control tester, which records data simultaneously. The quasistatic compression test is carried out by displacement control. The loading rate is $1 \mathrm{~cm} / \mathrm{s}$.

Since it is inconvenient to observe the deformation of the top, bottom, and inside of the energy absorption device during the test, ABAQUS2017 software is used to simulate the test process to observe the whole deformation process of the energy absorption device. In the process of numerical simulation, density, elasticity, and plasticity are used to describe the strength/strain criterion of materials, and the size and material of the device are consistent with the test. A downward displacement rigid plate is set at the top of the device to replace the compression rigid plate, and the displacement speed is consistent with the test loading speed. A fixed rigid plate is set at the bottom of the device. The device and the rigid plate are set as the friction contact relationship, and the friction coefficient is set as 0.45 (it is found that when the friction coefficient is taken as 0.45 , the numerical results are in good agreement with the test results). The device is divided into 13500 elements and 13709 nodes. The size of the device and numerical model is shown in Figure 3.

2.1.2. Deformation Process. As shown in Figure 4, the deformation process of experiment is the same as that of numerical simulation.

\subsubsection{Load-Displacement Curve and Its Segmentation.} The load-displacement curve of the device obtained by numerical simulation and experiment is shown in Figure 5. The two curves are similar, which prove that the numerical model is correct. According to the ascending and descending trend of the load curve, the curve is divided into five stages by a dotted line, namely, the first ascending section, the first descending section, the second ascending section, the second descending section, and the third ascending section. The compression height from $0-25 \mathrm{~mm}$ is the first ascending section of the device, and at this stage, the load value 


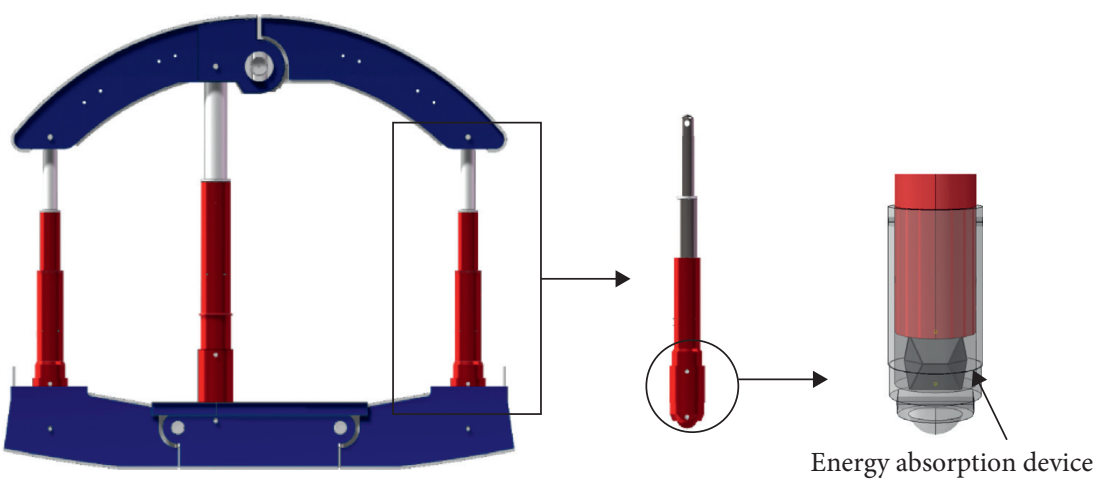

Figure 1: Location of the energy absorbing device.

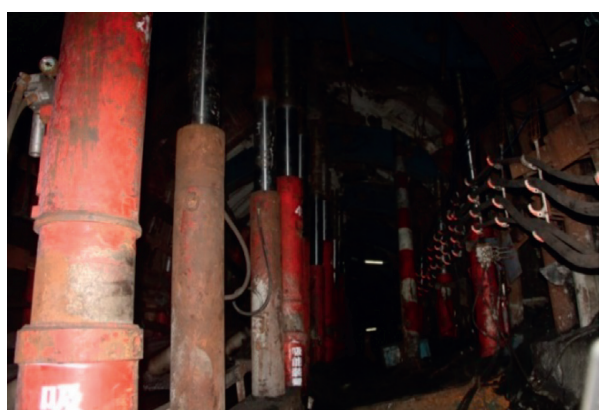

FIgURE 2: Field application drawing of energy absorbing support in the Gengcun mine, Henan Province, China.

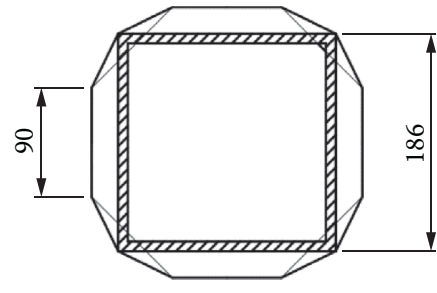

(a)

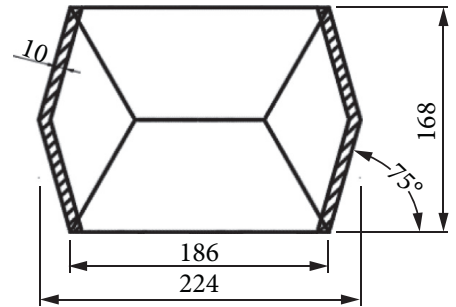

(b)

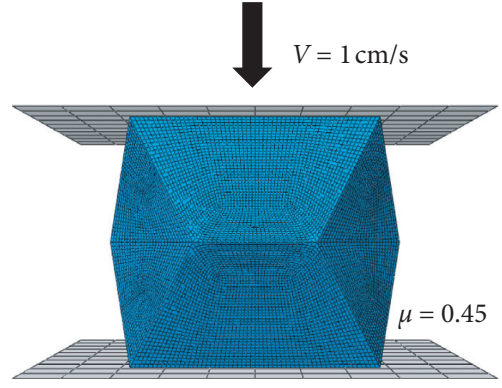

(c)

Figure 3: Dimension model of the energy absorption device: (a) main view of the device; (b) main view of the device; and (c) numerical model of the device.
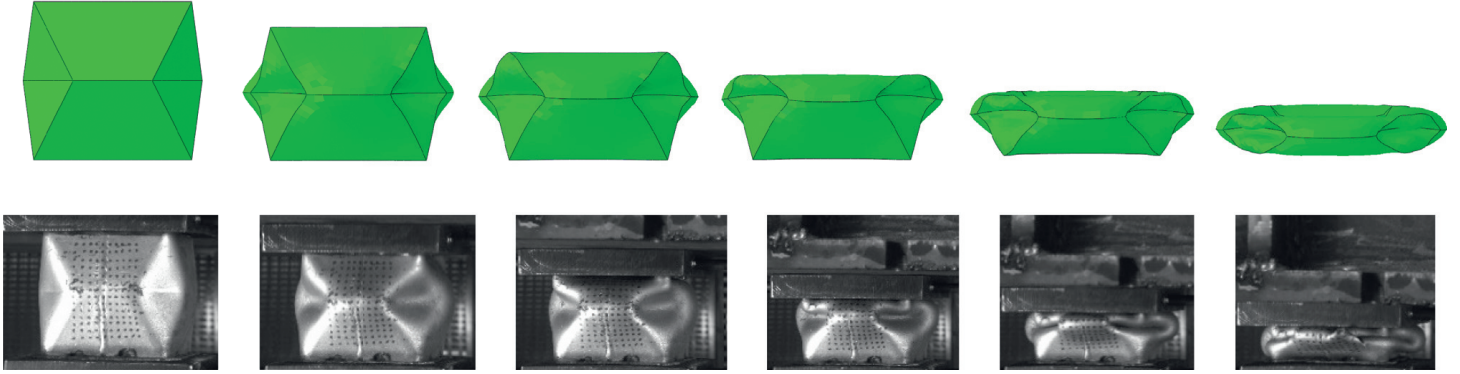

FIGURE 4: Comparison between numerical simulation and the experimental deformation process. 


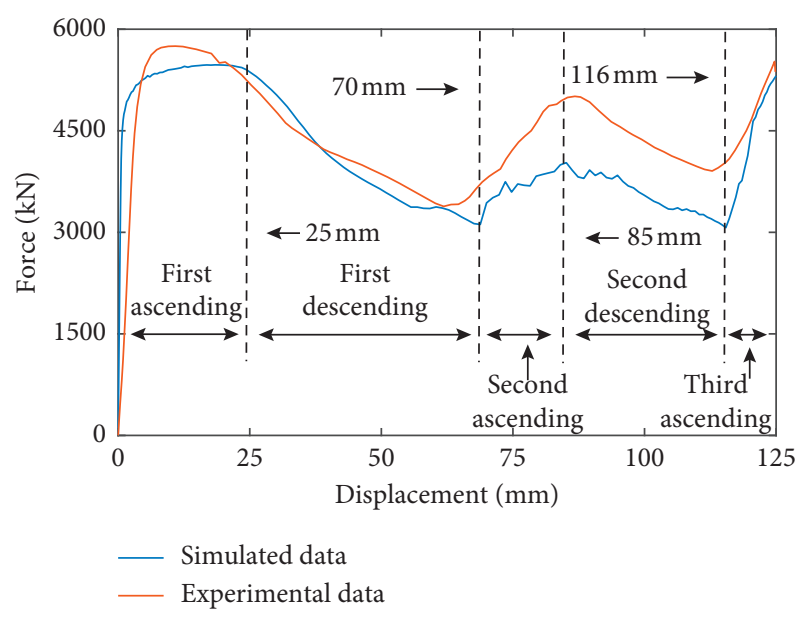

FIgURE 5: Comparison of numerical simulation and the test loaddisplacement curve.

increases to $5401 \mathrm{kN}$. From $25-70 \mathrm{~mm}$ is the first descending section, and the load value drops to $3116 \mathrm{kN}$. From $70-85 \mathrm{~mm}$ is the second ascending section. At this stage, the load value increases to $4029 \mathrm{kN}$. From $85-116 \mathrm{~mm}$ is the second descending section. At this stage, the load value decreases to $3069 \mathrm{kN}$. After the compression height is greater than $116 \mathrm{~mm}$ is third ascending section, the energy absorption device has been completely compressed, and the energy absorption device is no longer able to absorb energy.

\subsection{Plastic Strain}

2.2.1. Analysis Area Division. In order to further analyse the cause of load change of the device, based on the symmetry of the device, 10 analysis areas are evenly selected on the convex side wall and concave side wall of the device, and the location of the analysis area is shown in Figure 6. Since the device absorbs the impact energy through plastic deformation, the plastic strain is taken as the research index to analyse the reason of the fluctuation of the load-displacement curve.

2.2.2. Plastic Strain in Each Area. The plastic strain (peeq-calculated according to formula (1)) curve of area 1-10 and the load-displacement curve of the device are shown in Figure 7. The load curve value is marked on the left longitudinal axis, and the plastic strain value is marked on the right longitudinal axis.

$$
\text { peeq }=\sqrt{\frac{2}{3} \varepsilon^{p l}: \varepsilon^{p l}}
$$

where peeq-plastic strain and - plastic strain increment.

In the first ascending section, the plastic strain increases to 0.27 in the area 3 and 0.70 in the area 8 . The plastic strain in the rest area changes little. In the first descending section, the plastic strain in area 2 increases to 0.34 , the plastic strain in area 6 rapidly increases to 2.13 when the load value decreases, and 0.51 in area 7 , and the plastic strain in other areas changes slightly. In the second ascending section, the plastic strain in 6,8 , and 10 areas increased slightly, and in 7 area, the plastic strain increased to 0.75 , while in the remaining areas, the plastic strain did not change much. In the second descending section, the plastic strain increases to 0.27 in convex side area 4, 0.52 in concave side area 9, and 1.97 in area 10 when the load value decreases again, while the plastic strain changes slightly in other areas.

2.2.3. Plastic Strain in the Deformation Process. Figure 8 is the plastic strain cloud picture of the device in the five stages mentioned above, where a-e is the main view and $f-j$ is the sectional view.

In the first ascending section, under the action of friction, the deformation of the upper and lower edges of the device is relatively small. Under the action of the upper load, the middle part of the convex side folds outwards and the middle part of the concave side folds inwards, indicating that the load rise of the device is closely related to the deformation of the middle part (as shown in Figures 8(b) and $8(\mathrm{~g}))$. Because the concave side is a parallelogram with small area and instability, it is squeezed by the adjacent convex side in the process of inward bending, showing a two-way stress state, so the plastic strain of the concave side is larger than that of the convex side.

In the first descending section, the friction load at the top of the device cannot maintain the stability of the top side wall. Under the action of the upper load, the convex side wall folds down to the parallel state (as shown in Figures 8(c)) and $8(\mathrm{~h})$ ). The plastic strain at the top and upper part of concave sidewall increases to a large extent, and the plastic deformation of other locations changes less, which indicates that the upper load is mainly borne by the top and upper region of concave side, and the convex side fails to play its bearing capacity. At this stage, the bearing capacity of the energy absorbing device decreases greatly, so the load-displacement curve decreases.

In the second ascending section, the lower part does not deform due to the large friction at the bottom of the energy absorbing device, and the upper side wall of the energy absorption device continues to press and deform under the pressure of the rigid plate. Because the upper side wall of the convex side has folded to the parallel state in the previous stage, the upper side wall of the convex side no longer continues to bear the load, so only the top of the concave side wall bears the load, and the concave side wall will deform under the pressure, which will drive the convex side wall to deform downward (as shown in Figures 8(d) and 8(i)). In this stage, the load-bearing area of the energy absorption device is greatly reduced compared with the previous stage, and the rigidity of the energy absorption device is unchanged, so the load required for the folding of the energy absorption device is greatly increased, resulting in the rise of the load-displacement curve.

In the second descending section, with the constant compression of the energy absorption device, the friction load at the bottom of the device cannot maintain the stability of the lower part of the energy absorption device. Under the action of the upper load, the lower side wall of the convex 


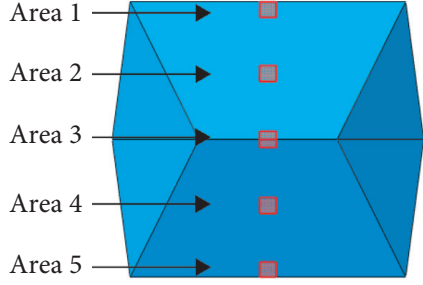

(a)
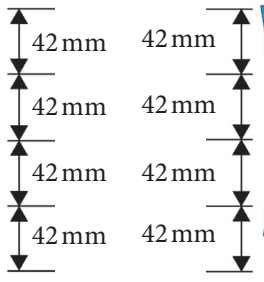

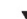

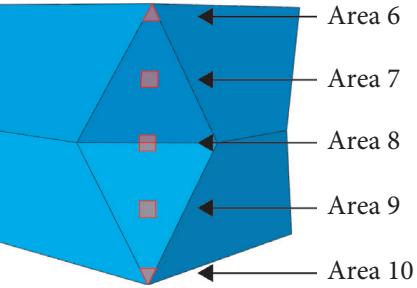

(b)

Figure 6: Analysis area of the energy absorption device: (a) concave side; (b) convex side.

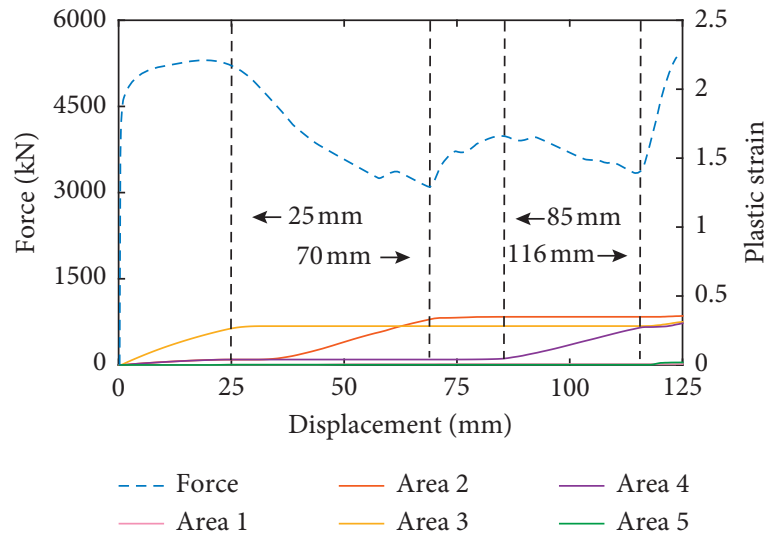

(a)

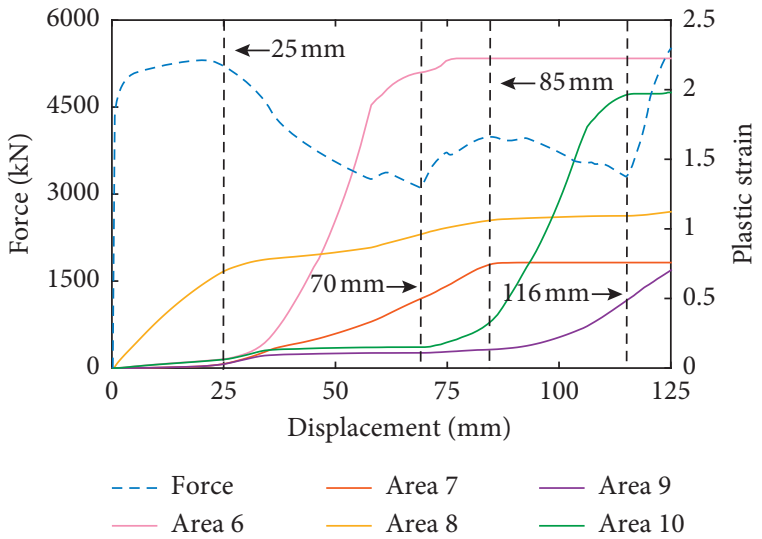

(b)

FIGURE 7: Load and plastic strain curve of each area of the device: (a) concave side wall; (b) convex side wall.

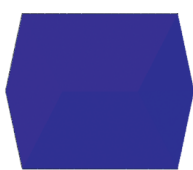

(a)

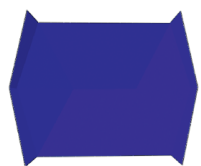

(f)

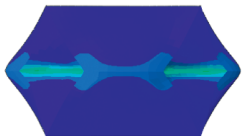

(b)

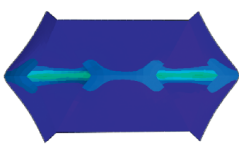

(g)

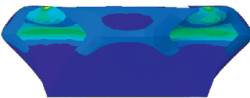

(c)

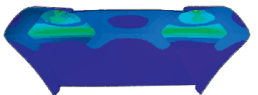

(h)

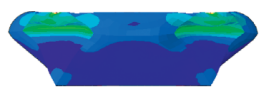

(d)

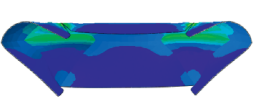

(i)

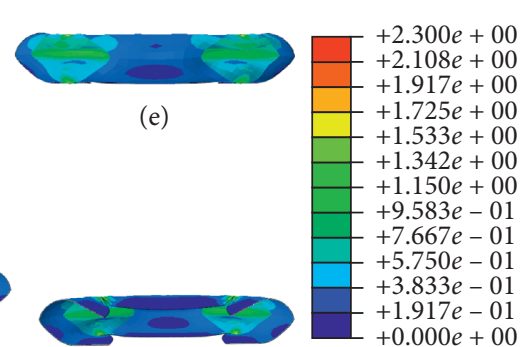

(j)

Figure 8: Plastic strain in deformation process: (a) main view of the device; (b) main view of the first ascending section; (c) main view of the first descending section; (d) main view of the second ascending section; (e) main view of the second descending section; (f) section view of the device; (g) section view of the first ascending section; (h) section view of the first descending section; (i) section view of the second ascending section; and (j) section view of the second descending section.

side folds up to the horizontal state (as shown in Figure 8). In this stage, the reason for load drop of the energy absorbing device is similar to that of the first descending section of the energy absorbing device. The plastic strain at the bottom and lower part of concave sidewall increases to a large extent, and the plastic deformation of other locations changes less, which indicates that the upper load is mainly borne by the bottom and lower region of the concave side, and the convex side fails to play its bearing capacity. At this stage, the bearing capacity of the energy absorbing device decreases greatly, so the load-displacement curve decreases.

\subsection{Main Influencing Factors}

2.3.1. Ideal Constant Resistance State. The principle of energy absorption support is when the rock burst occurs in the tunnel, the energy absorption device releases the impact energy of the surrounding rock through the yield 
deformation to avoid the failure of the support system due to the impact. At the same time, the energy absorption device always provides a certain bearing capacity during the yield process to prevent the damage of the tunnel due to the loss of bearing capacity.

According to the abovementioned quasistatic compression test results, it is found that the minimum bearing capacity of the existing device is only half of the maximum bearing capacity, and the large decline of the bearing capacity of the device will cause the tunnel to be damaged due to the loss of support capacity. At the same time, in the process of rapid deformation of the energy absorption device, when the reaction load rises again, the main loadbearing object will be transferred from the device to the upper support system, and then, the upper support system of energy absorption device will be damaged and fail.

Therefore, the load-displacement curve of the device in the ideal state should be a constant resistance state (as shown in Figure 9) in which the reaction load remains unchanged or changes little after the collapse. That is to say, when the tunnel is impacted, the energy absorption device can rapidly deform and provide a constant bearing capacity, so as to release the impact and avoid the stress concentration in the surrounding rock of the tunnel and prevent the tunnel from being damaged due to unloading too fast.

2.3.2. Main Influencing Factors. In the first and second descending sections of the device, because the upper and lower side walls of the convex side fail to play their bearing capacity, the load is mainly borne by the upper and lower part of the concave side wall, so the bearing capacity of the device is greatly reduced, and the load value is reduced.

When the first descending section is completed, the upper side wall of the convex side of the device folds to the parallel state and no longer bears the load. Because the friction load has a large binding load on the bottom of the device, the bottom of the device cannot be deformed, and the upper part continues to deform.

\section{Constant Resistance Device}

\subsection{The Influence of Concave Side Stiffness}

3.1.1. Different Thicknesses. The thickness of steel used in the mold of device is $10 \mathrm{~mm}$. For the convenience of subsequent production, the thickness of thickened steel is $10 \mathrm{~mm}$; this means, the local thickness of the device is increased from the initial $10 \mathrm{~mm}$ to $20 \mathrm{~mm}$. Select the thickening height as $1 / 12$, $2 / 12,3 / 12,4 / 12$, and $5 / 12$ of the overall height of the energy absorption device, i.e., $14 \mathrm{~mm}, 28 \mathrm{~mm}, 42 \mathrm{~mm}, 56 \mathrm{~mm}$, and $70 \mathrm{~mm}$ for calculation and analysis (as shown in Figure 10). After the calculation, the stability degree of the load-displacement curve is judged by variance, and the device with the smallest variance is selected as the optimal structure.

The variance data of the load-displacement curve of the device under different thicknesses is listed in Table 1. It can be seen from Table 1 that when the local thickening height is $42 \mathrm{~mm}$, the load- displacement curve variance of the device

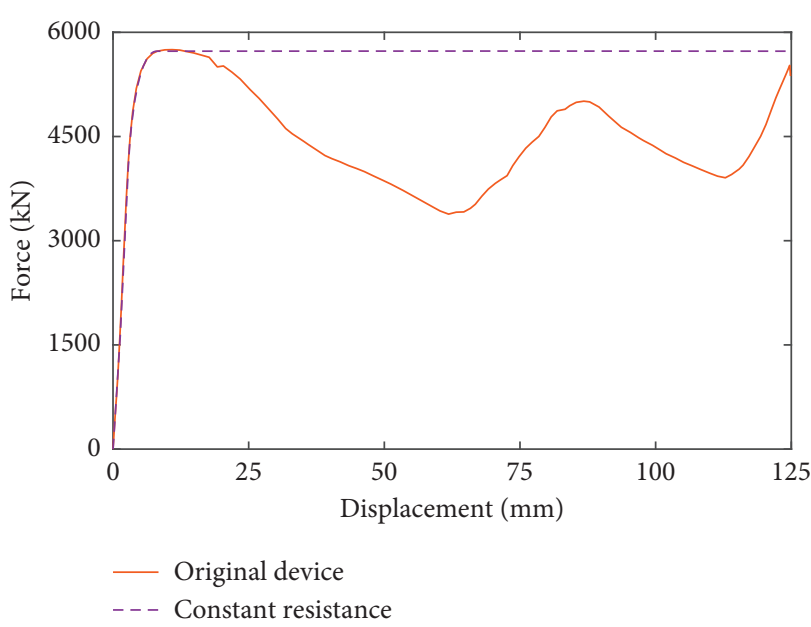

FIGURE 9: Load-displacement curve of the constant resistance state.

is the smallest, which is $1.15 \times 10^{5}$. The results of the loaddisplacement curve of the device at different thicknesses are listed in Figure 11. It can be seen from the figure that, with the increase in thicknesses, the maximum bearing capacity of the device increases gradually, and the descending section decreases gradually. Figure 12 is the comparison diagram of the load-displacement curve between the original structure and the local thickening structure when the thickening thickness is $42 \mathrm{~mm}$. It can be seen from Figure 13 that the amplitude of the descending section of the thickened structure is significantly reduced compared with the original structure.

3.1.2. Plastic Strain. Using the same method as mentioned above, 10 analysis areas are selected evenly on the concave convex side wall of the local thickened structure. The plastic strain curve of area 1-10 and the load-displacement curve of the device are shown in Figure 13. The value of the load curve is marked on the left longitudinal axis, and the value of the plastic strain is marked on the right longitudinal axis. Compared with the original structure curve (as shown in Figures 13 and 14), the plastic strain of the top, upper, lower, and bottom of the concave side of the thickened structure is significantly reduced, and the amplitude of the first and second descending sections is also significantly reduced. The results show that the structural thickening can effectively improve the stiffness of the abovementioned four parts, restrain the deformation of the abovementioned four parts, and reduce the amplitude of the descending section, which is consistent with the abovementioned analysis results.

3.1.3. The Influence of the Friction Coefficient. The friction coefficient has a great influence on the deformation and load-displacement curve of the device, so the mechanical properties of the device are analysed when the friction coefficient of the contact surface is $0.1-0.5$.

The variance of the load-displacement curve of the device under different friction coefficient conditions is listed in Table 2. Figure 15 is the load-displacement curve of the 


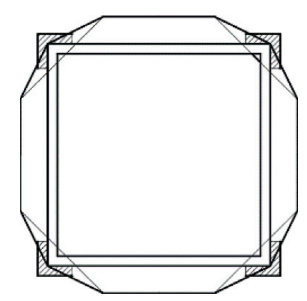

(a)

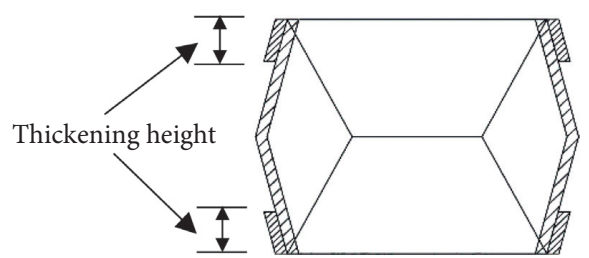

(b)

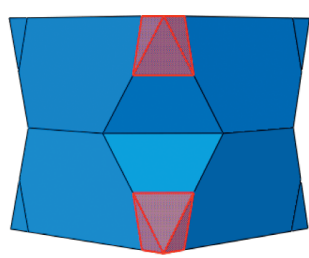

(c)

Figure 10: Thickened position of the device. (a) Top view, (b) main view, and (c) thickened area.

TABLE 1: Variance results of the load-displacement curve of the device with different thicknesses.

\begin{tabular}{|c|c|c|c|c|c|}
\hline Thickening height & $14 \mathrm{~mm}$ & $28 \mathrm{~mm}$ & $42 \mathrm{~mm}$ & $56 \mathrm{~mm}$ & $70 \mathrm{~mm}$ \\
\hline Variance & $2.57 \times 10^{5}$ & $1.84 \times 10^{5}$ & $1.15 \times 10^{5}$ & $2.16 \times 10^{5}$ & $4.07 \times 10^{5}$ \\
\hline
\end{tabular}

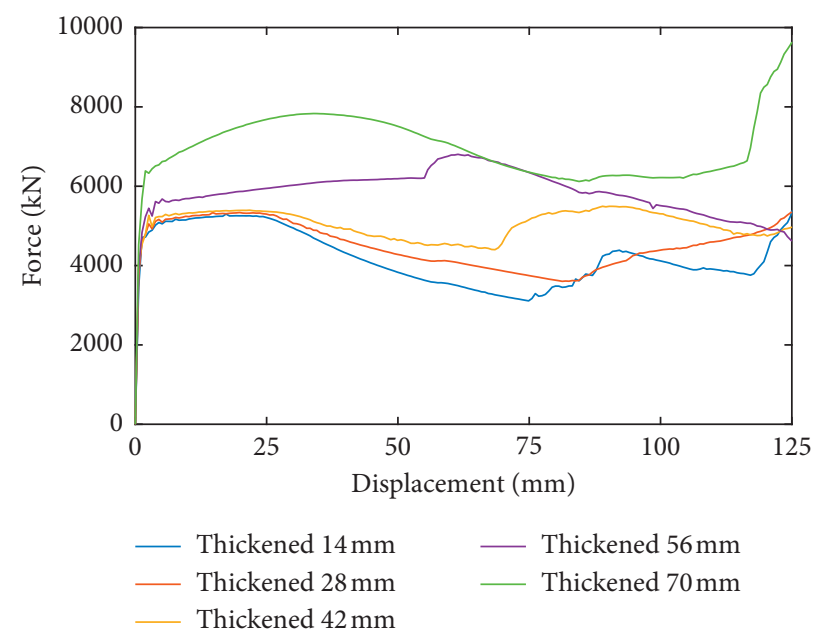

FIGURE 11: Load-displacement curve of the device under different thickening height conditions.

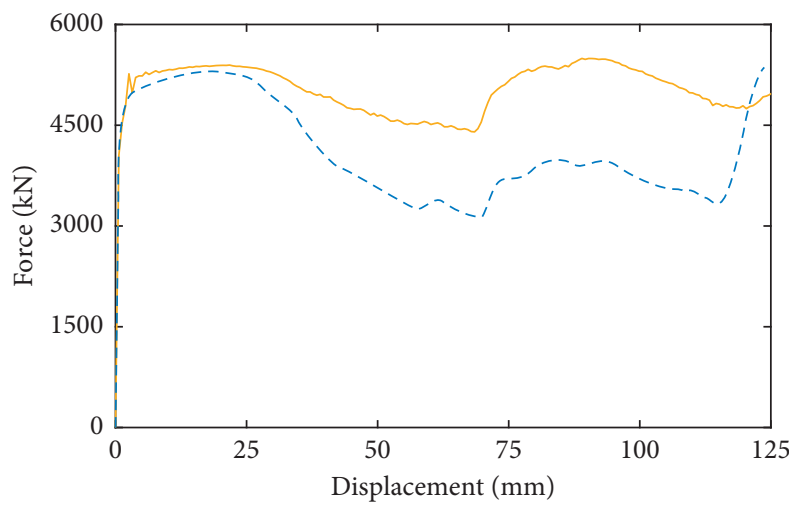

- - The origin structure

Thickened $42 \mathrm{~mm}$ structure

Figure 12: Comparison of the load-displacement curve between the structure with a thickness of $42 \mathrm{~mm}$ and the original structure. 


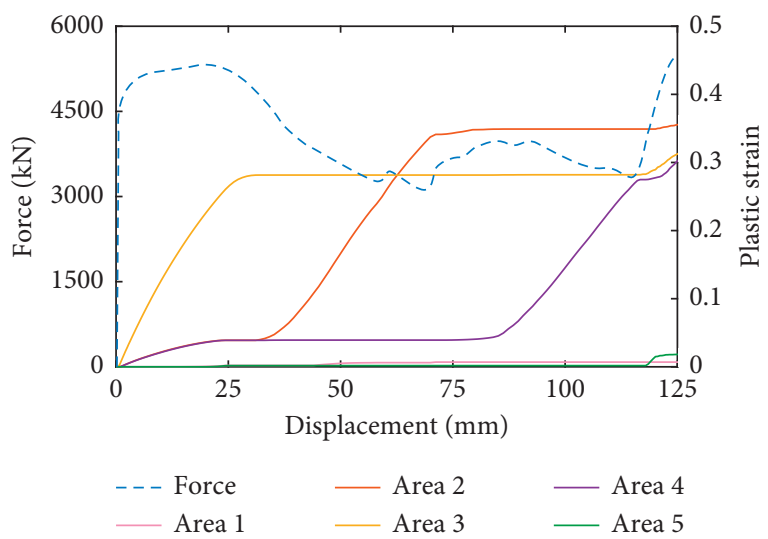

(a)

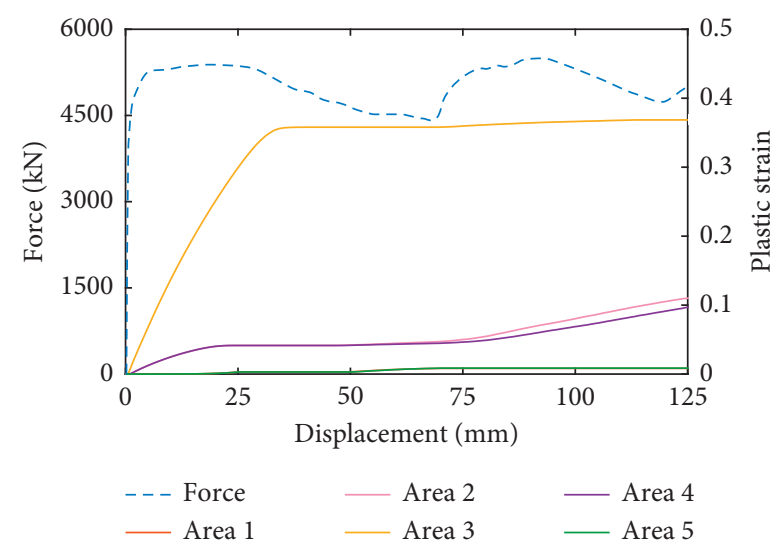

(b)

FIGURE 13: Displacement curve of load and plastic strain of each analysis area on the convex side of device (a) before thickened and (b) after thickened.

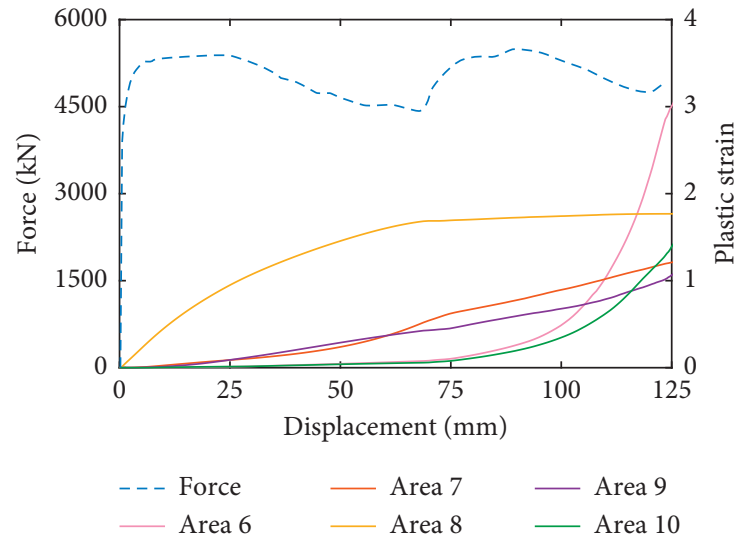

(a)

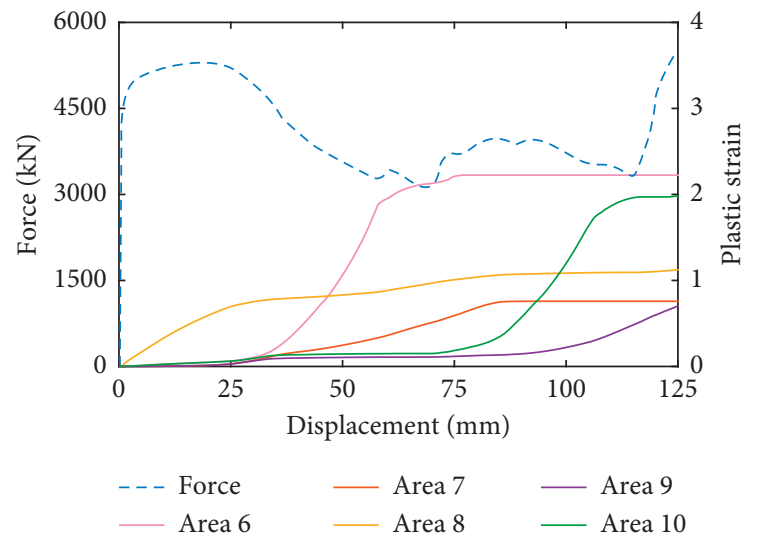

(b)

FIGURE 14: Displacement curve of load and plastic strain of each analysis area on the concave side of the device (a) before thickened and (b) after thickened.

TABle 2: Variance of the load-displacement curve of the energy absorption device with a different friction coefficient.

\begin{tabular}{lccccc}
\hline$f$ & 0.1 & 0.2 & 0.3 & 0.4 & 0.5 \\
\hline Variance & $9.12 \times 10^{4}$ & $5.92 \times 10^{4}$ & $7.76 \times 10^{4}$ & $1.32 \times 10^{5}$ & $3.18 \times 10^{5}$ \\
\hline
\end{tabular}

device under different friction coefficient conditions. It can be seen from Table 2 that the curve variance can be reduced by reducing the friction coefficient. When the friction coefficient is 0.2 , the curve variance is the smallest, which is $5.92 \times 10^{4}$. It can be seen from Figure 15 that, as the friction coefficient decreases, the maximum bearing capacity of the device decreases gradually, and curve is smoothed.

Figure 16 is a comparison diagram of the load-displacement curve of the structure and the original structure under the condition of a friction coefficient of 0.2 . The curve variance is reduced from $3.60 \times 10^{5}$ to $5.92 \times 10^{4}$. Figure 17 is a diagram of the deformation process under the condition of a friction coefficient of 0.2 . It can be seen from Figure 17 that the top side wall of the device first bends, then the bottom side wall bends, and finally, the middle part is bent until the energy absorption device is completely crushed. Due to the small friction coefficient, when the upper side wall of the device is bent to the parallel state, the friction load at the bottom of the device cannot maintain the stability of the bottom, so the bottom is deformed, and the process of the second ascending section does not occur.

3.2. New Type Device. The structure with the least variance of the load-displacement curve is selected as the constant resistance structure by considering the different friction coefficient and thickening height. Among them, the friction coefficient is $0.1-0.5$, respectively, and the thickening height is $1 / 12,2 / 12,3 / 12,4 / 12$, and $5 / 12$ of the overall height of the energy absorption device, namely, $14 \mathrm{~mm}, 28 \mathrm{~mm}, 42 \mathrm{~mm}$, $56 \mathrm{~mm}$, and $70 \mathrm{~mm}$.

The variance data are listed in Table 3. It can be seen from Table 3 that when the friction coefficient of the contact surface is 0.1 and the thickening height is $56 \mathrm{~mm}$, 


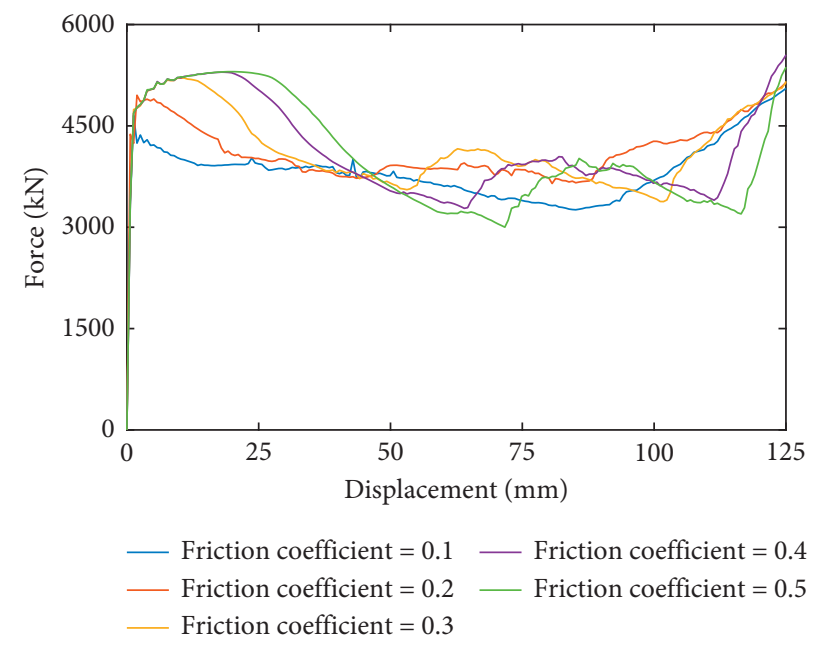

Figure 15: Load-displacement curve of the device under a different friction coefficient.

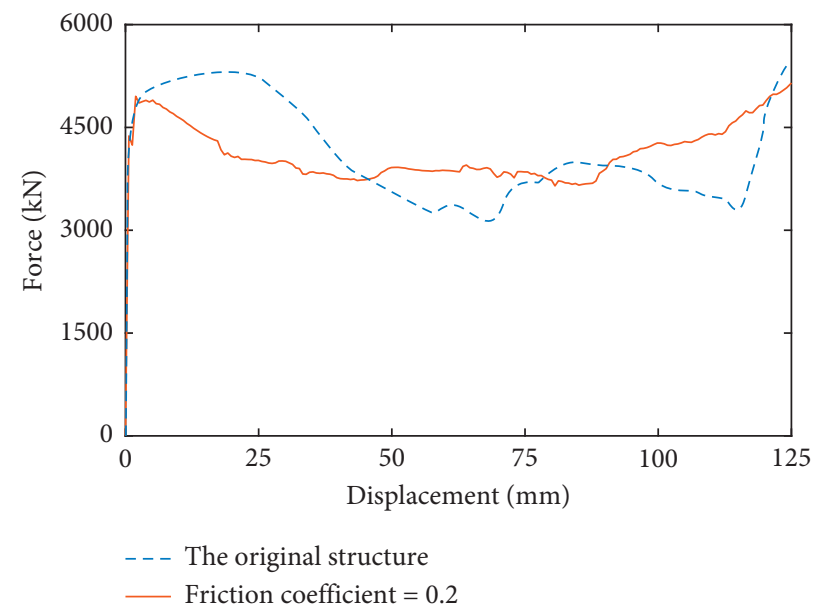

FIGURE 16: Comparison of the load-displacement curve between a friction coefficient of 0.2 and the original structure.

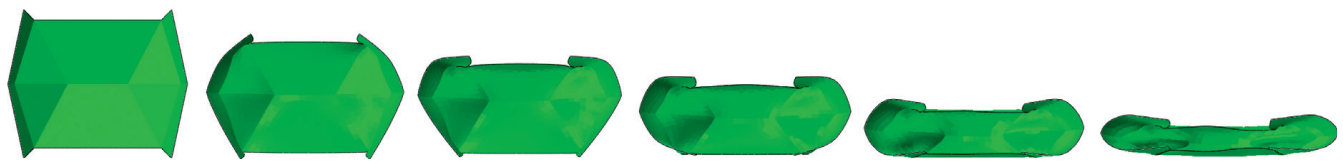

FIgURE 17: Deformation process of the device under the friction coefficient of 0.2.

the variance of the load- displacement curve of the device is the smallest, which is $8.91 \times 10^{3}$. The comparison diagram of the load-displacement curve between the new structure and the original structure is shown in Figure 18. The fluctuation of the load-displacement curve of the new structure is small, basically reaching the "constant resistance state." The comparison of the energy absorption effect between the new structure and the old structure is shown in Table 4. The total energy absorption $E$ and specific energy absorption SEA are calculated according to formulae (1) and (2). Under the condition of keeping the maximum bearing capacity unchanged, the average bearing capacity of the new structure is increased by $29 \%$, the total energy absorption is increased by $111 \%$, the specific energy absorption is $119 \%$, and the variance of the load-displacement curve is reduced to $3 \%$ of the original structure.

The total energy absorption $E$ is calculated according to formula (2), which refers to the area of compression load $\mathrm{P}$ under the compression displacement $\mathrm{U}$ curve. 
TABLE 3: Variance of the load-displacement curve of the device under a different friction coefficient and different thickening height.

\begin{tabular}{|c|c|c|c|c|c|}
\hline \multirow{2}{*}{$H$} & \multicolumn{5}{|c|}{$f$} \\
\hline & 0.1 & 0.2 & 0.3 & 0.4 & 0.5 \\
\hline 0 & $9.12 \times 10^{4}$ & $5.92 \times 10^{4}$ & $7.76 \times 10^{4}$ & $1.32 \times 10^{5}$ & $3.18 \times 10^{5}$ \\
\hline 14 & $1.92 \times 10^{5}$ & $1.21 \times 10^{5}$ & $1.09 \times 10^{5}$ & $2.07 \times 10^{5}$ & $3.22 \times 10^{5}$ \\
\hline 28 & $2.37 \times 10^{5}$ & $2.19 \times 10^{5}$ & $2.05 \times 10^{5}$ & $2.08 \times 10^{5}$ & $1.86 \times 10^{5}$ \\
\hline 42 & $1.90 \times 10^{5}$ & $1.64 \times 10^{5}$ & $1.29 \times 10^{5}$ & $1.16 \times 10^{5}$ & $1.13 \times 10^{5}$ \\
\hline 56 & $8.91 \times 10^{3}$ & $2.84 \times 10^{4}$ & $7.83 \times 10^{4}$ & $1.59 \times 10^{5}$ & $2.53 \times 10^{5}$ \\
\hline 70 & $1.68 \times 10^{5}$ & $2.07 \times 10^{5}$ & $2.61 \times 10^{5}$ & $3.54 \times 10^{5}$ & $4.49 \times 10^{5}$ \\
\hline
\end{tabular}

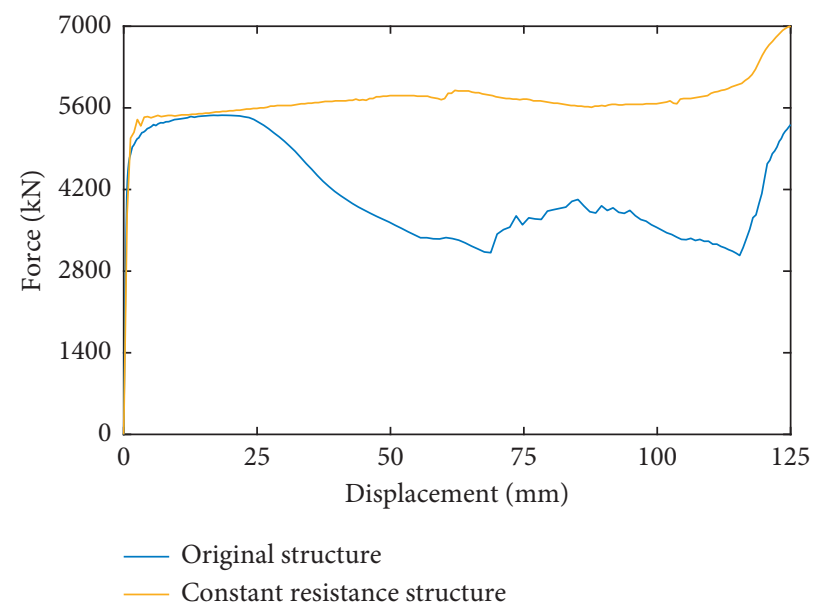

FIGURE 18: Comparison of the load-displacement curve between the new structure and original structure.

TABLE 4: Comparison of the energy absorption effect of original and new energy absorption devices.

\begin{tabular}{|c|c|c|c|c|c|}
\hline & $P_{\max }(\mathrm{kN})$ & $P_{\text {mean }}(\mathrm{kN})$ & $E(\mathrm{~kJ})$ & SEA $(\mathrm{kJ})$ & $S^{2}$ \\
\hline The original & 5750 & 4378 & 477.2 & 43.8 & $3.60 \times 10^{5}$ \\
\hline New device & 5430 & 5630 & 1007 & 96 & $8.91 \times 10^{3}$ \\
\hline Percentage (new/original) & $94 \%$ & $129 \%$ & $211 \%$ & $219 \%$ & $3 \%$ \\
\hline
\end{tabular}

$$
E=\int_{0}^{u} P(x) \mathrm{d} x .
$$

Specific energy absorption (SEA) refers to the energy absorbed by the unit mass of the structure within the effective crushing distance:

$$
\mathrm{SEA}=\frac{E}{m}=\frac{\int_{0}^{u} P(x) \mathrm{d} x}{m},
$$

where $E$-total energy absorption and $m$-mass of the energy absorbing device.

\section{Conclusions}

(1) Through the quasistatic compression experiment, the deformation process and mechanical properties of the device are studied. The results show that the loaddisplacement curve of the device is fluctuating during the crush process. The first and second descending of the curve are greatly affected by the concave side stiffness, and the second upcomer of the curve is greatly affected by the contact surface friction.

(2) The plastic strain of concave sides wall rapidly increase which relates to the load decrease, and improving this area can improve the energy absorption capacity of the device.

(3) The stiffness of the concave side is increased by thickening, which effectively reduces the amplitude of the curve descent. Whether continuous deformation occurs is affected by reducing the friction coefficient.

(4) A new type of the constant resistance structure is designed by thickening and reducing the friction coefficient of the device. Compared with the original structure, the maximum bearing capacity of the new type of the constant resistance structure is basically unchanged, the average bearing capacity is increased by $29 \%$, the total energy absorption is increased by $111 \%$, the specific energy absorption is increased by 
$119 \%$, and the curve variance is reduced to $3 \%$ of the original structure.

\section{Data Availability}

The data used to support the findings of this study are available from the corresponding author upon request.

\section{Conflicts of Interest}

The authors declare no conflicts of interest.

\section{Acknowledgments}

This work was supported by the National Natural Science Foundation of China (nos. 51474013 and 51774015) and Youth Talent Support Program of North China University of Technology.

\section{References}

[1] Y. S. Pan, Z. H. Li, and M. T. Zhang, "Distribution, type, mechanism and prevention of rockbrust in China," Chinese Journal of Rock Mechanics and Engineering, vol. 22, no. 11, pp. 1844-1851, 2003.

[2] Y. D. Jiang, Y. X. Zhao, W. G. Liu et al., Investigation on the Mechanism of Coal Bumps and Relating Experiments, pp. 20-21, Science Press, Beijing, China, 2009.

[3] K. Skrzypkowski, W. Korzeniowski, K. Zagórski, and A. Zagórska, "Adjustment of the yielding system of mechanical rock bolts for room and pillar mining method in stratified rock mass," Energies, vol. 13, no. 8, p. 2082, 2020.

[4] K. Skrzypkowski, "A new design of support for burst-prone rock mass in underground ore mining," E3S Web of Conferences, vol. 71, p. 6, 2018.

[5] J. F. Pan, S. W. Wang, S. H. Liu et al., "Practices and monitoring method of static loading dominant type mine strata pressure bump in shallow depth mine," Coal Science and Technology, vol. 44, no. 6, 2016.

[6] D. W. Si, "Analysis of coal mine rock burst accident based on "4M factor"” Coal Mine Modernization, vol. 3, 2017.

[7] K. X. Wang and Y. S. Pan, "An unified theory of energy absorption and anti-impact for surrounding rock and support in rock burst mine," Rock and Soil Mechanics, vol. 36, no. 9, 2015.

[8] Y.S. Pan, X. Ma, Y. H. Xiao, and Z. H. Li, "Numerical analysis and experimental study of a coal mine anti-impact and energy-absorption supporting component," Journal of Experimental Mechanics, vol. 29, no. 2, pp. 231-238, 2014.

[9] J. Q. Chen, X. M. Zhou, J. Q. Rao et al., "A research on the impact energy absorption characteristics and optimization of thin-walled structure of vehicle front rail," Automotive Engineering, vol. 32, no. 6, 2010.

[10] S. Desjardins, "The evolution of energy absorption systems for crashworthy helicopter seats," Journal of the American Helicopter Society, vol. 51, no. 2, 2006.

[11] W. Guan, G. Gao, J. Li, and Y. Yu, "Crushing analysis and multi-objective optimization of a cutting aluminium tube absorber for railway vehicles under quasi-static loading," Thin-Walled Structures, vol. 123, pp. 395-408, 2018.

[12] J. K. Paik, B. J. Kim, D. K. Park, and B. S. Jang, "On quasi-static crushing of thin-walled steel structures in cold temperature: experimental and numerical studies," International Journal of Impact Engineering, vol. 38, no. 1, pp. 13-28, 2011.

[13] W.-Y. Jang and S. Kyriakides, "On the crushing of aluminum open-cell foams: Part I. Experiments," International Journal of Solids and Structures, vol. 46, no. 3-4, pp. 617-634, 2009.

[14] H. Y. Song, "Simulation of mechanical properties of single -walled carbon nanotubes by molecular dynamics," Journal of Xi'an University of Post and Telecommunications, vol. 13, no. 1, 2008.

[15] W.-Y. Jang and S. Kyriakides, "On the crushing of aluminum open-cell foams: Part II analysis," International Journal of Solids and Structures, vol. 46, no. 3-4, pp. 635-650, 2009.

[16] T. X. Yu, "Impact energy absorbing devices based upon the plastic deformation of metallic elements," Advances in Mechanics, vol. 16, no. 1, pp. 28-39, 1986.

[17] S. C. K. Yuen and G. N. Nurick, "The energy-absorbing characteristics of tubular structures with geometric and material modifications: an overview," Applied Mechanics Reviews, vol. 61, no. 2, 2008.

[18] W. Abramowicz, "Thin-walled structures as impact energy absorbers," Thin-walled Structures, vol. 41, no. 2-3, 2003.

[19] Y. Liu, "Crashworthiness design of multi-corner thin-walled columns," Thin-walled Structures, vol. 46, no. 12, pp. 1329-1337, 2008.

[20] K. Yamazaki and J. Han, "Maximization of the crushing energy absorption of cylindrical shells," Advances in Engineering Software, vol. 31, no. 6, pp. 425-434, 2000.

[21] A. A. A. Alghamdi, "Collapsible impact energy absorbers: an overview," Thin-Walled Structures, vol. 39, no. 2, 2001.

[22] A. G. Hanssen, M. Langseth, and O. S. Hopperstad, "Static and dynamic crushing of circular aluminium extrusions with aluminium foam filler," International Journal of Impact Engineering, vol. 24, no. 5, 2000.

[23] Ø. Jensen, O. S. Hopperstad, and M. Langseth, "Transition from progressive to global buckling of aluminium extrusions-a numerical study," International Journal of Crashworthiness, vol. 10, no. 6, pp. 609-620, 2005.

[24] F. Yang, P. Wang, H. L. Fan et al., "Review of theoretical models on the energy absorption and deformation modes of the thin-walled tubular structures," Chinese Quarterly of Mechanics, vol. 39, no. 4, 2018.

[25] X. Ma, Y. S. Pan, J. Z. Zhang et al., "Design and performance research on core energy absorption component of anti-impact support," Journal of China Coal Society, vol. 43, no. 4, 2018.

[26] Z. Tang, Y. S. Pan, Q. Li et al., "Numerical analysis of energyabsorption properties of a thin-walledcomponent with square folds for rock burst prevention in mine," Journal of Vibration and Shock, vol. 33, no. 23, 2014.

[27] X. Ma, Y. S. Pan, Y. H. Xiao et al., "Study on buckling energyabsorption properties of induced supporting device for rock burst prevention," Journal of Safety Science and Technology, vol. 12, no. 6, 2016.

[28] Y. S. Ma, J. Pan, Z. Zhang et al., "Influence of plate inclination angle on energy absorption characteristics of pre-folded edge tube anti-scour and supporting device," China Safety Science Journal, vol. 27, no. 1, 2017.

[29] Y. S. Pan, Y. H. Xiao, Z. H. Li et al., "Study of tunnel support theory of rockburst in coal mine and its application," Journal of China Coal Society, vol. 39, no. 2, 2014.

[30] W. Abramowicz and N. Jones, “Transition from initial global bending to progressive buckling of tubes loaded statically and dynamically," International Journal of Impact Engineering, vol. 19, no. 5-6, pp. 415-437, 1997. 